\title{
Correction: Youth Experiences With Referrals to Mental Health Services in Canada: Protocol for a Web-Based Cross-Sectional Survey Study
}

Shalini Lal ${ }^{1,2,3,4}$, BSc, MSc, PhD; Danielle Joanna Starcevic ${ }^{2,5}$, BSc, MSc; Rebecca Fuhrer ${ }^{3,5}$, BA, MSc, PhD

\footnotetext{
${ }^{1}$ School of Rehabilitation, Faculty of Medicine, University of Montréal, Montréal, QC, Canada

${ }^{2}$ Youth Mental Health and Technology Lab, University of Montréal Hospital Research Centre, Montréal, QC, Canada

${ }^{3}$ ACCESS Open Minds (Pan-Canadian Youth Mental Health Services Research Network), Douglas Mental Health University Institute, Montréal, QC, Canada

${ }^{4}$ Prevention and Early Intervention Program for Psychosis (PEPP), Douglas Mental Health University Institute, Montréal, QC, Canada

${ }^{5}$ Dept of Epidemiology, Biostatistics and Occupational Health, Faculty of Medicine, McGill University, Montréal, QC, Canada
}

\section{Corresponding Author:}

Shalini Lal, BSc, MSc, PhD

School of Rehabilitation, Faculty of Medicine

University of Montréal

CP 6128, succursale Centre-ville

Montréal, QC, H3C 3J7

Canada

Phone: 15148908000 ext 31676

Email: shalini.lal@umontreal.ca

\section{Related Article:}

Correction of: https://www.researchprotocols.org/2020/3/e16945/

(JMIR Res Protoc 2020;9(6):e19019) doi: 10.2196/19019

In "Youth Experiences With Referrals to Mental Health Services in Canada: Protocol for a Web-Based Cross-Sectional Survey Study" (JMIR Res Protoc 2020;9(3):e16945) the authors noted a footnote was erroneously omitted from the text of Multimedia Appendix 2. The footnote has been added to Multimedia Appendix 2, and is positioned under the question "What are the ethnic or cultural origins of your ancestors? [Please check all that apply]". The footnote reads:

Ethnicity question and responses were adapted using information from the following documents: 1) Statistics Canada Census of Population 2016, Appendix 5.1 Ethnic Origins disseminated from 2016, 2011, and 2006. Retrieved from: https://www12. statcan.gc.ca/census-recensement/2016/ref/dict/ app-ann/a5_1-eng.cfm, 2) Archived Census 2A-L 2016. Retrieved from: http://www23.statcan.gc.cal imdb/p3Instr.pl? Function= getInstrumentList \& Item_Id $=295122 \& U L=1 V \&$, 3) Ethnic Origin
Reference Guide, Census of Population, 2016.

Retrieved from: https://www12.statcan.gc.cal census-recensement $/ 2016 /$ ref/guides $/ 008 /$ 98-500-x2016008-eng.cfm \& 4) Data Tables 2016 Census: Ethnic Origins. Retrieved from: https:/ /www12.statcan.gc.ca/census-recensement/2016/ $d p-p d / d t-t d / A v-e n g . c f m$ ? LANG $=E \&$ $A P A T H=3 \& D E T A I L=0 \& D I M=1 \& F L=A \& F R E E=0 \&$ $G C=0 \& G I D=0 \& G K=0 \& G R P=1 \& P I D=112450 \&$ $P R I D=10 \& P T Y P E=109445 \& S=0 \&$ $S H O W A L L=0 \& S U B=0 \&$ Temporal $=2017 \&$ $T H E M E=120 \& V I D=29591 \& V N A M E E=\& V N A M E F=$

The corrected Multimedia Appendix 2 file will be uploaded to the online version of the original paper on the JMIR website on June 12, 2020, together with the publication of this correction notice. Because this was made after submission to PubMed, PubMed Central, and other full-text repositories, the corrected article has also been resubmitted to those repositories.

\section{Multimedia Appendix 2}

Questionnaire.

[DOCX File, $80 \mathrm{~KB}-$ Multimedia Appendix 2] 
This is a non-peer-reviewed article. Submitted 15.04.20; accepted 16.04.20; published 12.06.20.

Please cite as:

Lal S, Starcevic DJ, Fuhrer R

Correction: Youth Experiences With Referrals to Mental Health Services in Canada: Protocol for a Web-Based Cross-Sectional Survey Study

JMIR Res Protoc 2020;9(6):e19019

URL: https://www.researchprotocols.org/2020/6/e19019

doi: $10.2196 / 19019$

PMID: $\underline{32530818}$

(C) Shalini Lal, Danielle Joanna Starcevic, Rebecca Fuhrer. Originally published in JMIR Research Protocols (http://www.researchprotocols.org), 12.06.2020. This is an open-access article distributed under the terms of the Creative Commons Attribution License (https://creativecommons.org/licenses/by/4.0/), which permits unrestricted use, distribution, and reproduction in any medium, provided the original work, first published in JMIR Research Protocols, is properly cited. The complete bibliographic information, a link to the original publication on http://www.researchprotocols.org, as well as this copyright and license information must be included. 